DeAr SIRS

\section{Teacher-student relationship}

Dr J. Wilson's interesting notes on his work with an experiential group of medical students (Bulletin, June 1987, 11, 194-195) showed how flaws in the teacher-student relationship can inhibit later development of the good doctor-patient relationship which, as he states, "underpins the whole of medical practice".

I am concerned that he makes no reference to the extensive published work of Michael and Enid Balint and their co-workers ${ }^{1.2 .3}$ on these important aspects of medical training. I admire Dr Wilson's skilful identification of his students' fears about the teacher-student relationship but I question the wisdom of interpreting such findings to the group without a follow-up scheme to help the students work through these anxieties.

The Balints limited their interpretations to the context of the doctor-patient relationship to avoid raising personal anxieties which could not be properly dealt with even in the setting of their longer term groups. The training seminars now organised by the Balint Society might offer further help for those students who wish to understand more about their relationship with their patients.

South Cottage, Ham Gate Avenue

Jean Pasmore

Richmond, Surrey

\section{ReFerences}

'BALINT, M. (1957) Training medical students in psychotherapy. Lancet, 2, 1015-1018.

2 _ \& E. (1961) Psychotherapeutic Techniques in Medicine. London: Tavistock.

3 _- - Gosling, R. \& Hildebrand, P. (1966) a Study of Doctors. London: Tavistock.

\section{DeAr Sirs}

\section{The legal aspects of psychiatry}

Dr D. A. Spencer writes to you in the June 1987 edition of the Bulletin arguing in favour of "the establishment within the College of a special branch to develop study experience, expertise, information and advice in the legal aspects of psychiatry". He makes the point that "forensic psychiatry, the application of psychiatry to the purposes of law and the administration of justice, is a different and separate entity".

Whilst agreeing with the latter point, I would suggest that, through the nature of their clinical practice and the legal and administrative context in which it occurs, forensic psychiatrists develop at least more acquaintance with legal aspects of psychiatry (perhaps even detailed legal knowledge) than do their general colleagues. Of course it would be entirely wrong in any way to limit contributions to debate and understanding in the area to specialist forensic psychiatrists; however, perhaps the Section of Forensic Psychiatry of the College would prove the natural focus for such contributions. I feel sure that the Forensic Section would welcome more general psychiatrists into its fold and there may be significant disadvantages arising from proliferation of special interest groups within the College.

Broadmoor Hospital

Nigel L. G. Eastman

\section{Proposed: A Preventive Psychiatry Specialist Group}

DeAr SIRS

Fellows and Members of the Royal College of Psychiatrists have the option of membership of the Specialist Sections and Groups which have provided the forum for some of the most interesting activities of the College. There are six of these Sections (Child and Adolescent, Forensic, Psychiatry of Mental Handicap, Psychiatry of Old Age, Psychotherapy and Social \& Community Psychiatry) and three Groups (Dependence/Addiction, Biological Psychiatry and Liaison Psychiatry).

Through conferences, workshops, lectures and symposia, these Sections and Groups provide a most valuable educational opportunity to the participants, whilst keeping the flame alive in the areas of their interest. Every area in which psychiatrists are currently active in a clinical, teaching or research capacity is covered. So it is understandable that there is no provision for the one area which everyone glosses over, but which happens to be the most important area of all: Preventive Psychiatry.

We have grown so accustomed to studying, diagnosing and treating illness that we hardly ever think in terms of health. Had it been otherwise, the prevention of mental disorder would have assumed a far greater place in our activities than anything else.

It might be argued that as we do not know the causes of most mental disorders, we could not possibly do anything to prevent them; or that the object of research in psychiatry is to find out as much as possible about mental disorders, with prevention as the ultimate goal.

Be that as it may, the prevention of mental disorders has not crystallised in our minds as a distinct objective to work at.

But we must begin to think seriously along these lines, for the simple reason that prevention is better than cure. Who among us would not be truly happy to see the incidence and prevalence of mental disorder vastly reduced? That would be cause for jubilation.

As I believe that the work of prevention will be vastly accelerated where there is a specific focus on this, I am at this time proposing that the College sets up a Preventive Psychiatry Specialist Group for all those who would like to pay specific attention to the prevention of mental disorders, and work towards it. Let us not be deterred by the fact that we do not know the causes of most mental disorders. We could begin with what we know, and work gradually towards the rest.

I believe that very many psychiatrists would be interested in a Preventive Psychiatry Specialist Group, and that such a Group would prove to be extremely successful.

I. O. AZUONYE

Claybury Hospital

Woodford Green, Essex

Council have agreed that special interest Groups should be formed and regulations for the establishment of such groups will be published in a future issue of the Bulletin. 